\title{
REAL TIME TRACKING AND HEALTH MONITORING OF SOLDIERS USING GPS AND GSM MODULE
}

Kumar kandukuri ${ }^{1}$ and R.Sindhuja ${ }^{2}$,D.Thasneem ${ }^{2}$

\begin{abstract}
This project gives an ability to track the location and monitor health of the soldiers who become lost and get injured in the battlefield. It helps to minimize the time, search and rescue operation efforts of army control unit. This system enables the army base station to track the location using GPS module and health monitoring using wireless biosensor such as temperature sensor, heart rate sensor, pressure sensor. The metal detector is also used here to detect land mines. The data coming from sensor and GPS receiver is transmitted through the GSM module. Also a soldier can ask help from control room and communicate with other soldiers who are present within the wireless transmission and reception range using panic button.
\end{abstract}

Keywords: Biosensors, wireless transmission, location tracking, landmine detection system.

\section{I.INTRODUCTION}

In today's world enemy warfare is an important factor in any nation's security. The national security mainly depends on army (ground), navy (sea), air-force (air). The important and vital role is played by the army soldier's. There are many concerns regarding the safety of these soldiers. As soon as any soldier enters the enemy lines it is very vital for the army base station to know the location as well as the health status of all soldiers. In our project we have come up with an idea of tracking the soldier as well as to give the health status of the soldier during the war, which enables the army personnel to plan the war strategies. By using the location sent by the GPS modem, the base station can understand the position of soldier and the panic button helps to communicate with other soldiers. Landmine detection is also used here to avoid some accidents during wars.

\section{II.PROPOSED METHOD}

This system mainly consist of three units are healthcare, location tracking and army base station. For healthcare sector some biosensors are used, for location tracking GPS is used and for transmitting informations to the army base

\footnotetext{
${ }^{1}$ Department Of BME Adhiyamaan College Of Engineering,Hosur-635109

${ }^{2}$ Department Of BME Adhiyamaan College Of Engineering,Hosur-635109
} 
station GSM is used. Panic button is used by soldiers at emergency situations. Landmines can be detected by metal detector.

This system mainly consist of three units are healthcare, location tracking and army base station. For healthcare sector some biosensors are used, for location tracking GPS is used and for transmitting informations to the army base station GSM is used. Panic button is used by soldiers at emergency situations. Landmines can be detected by metal detector.

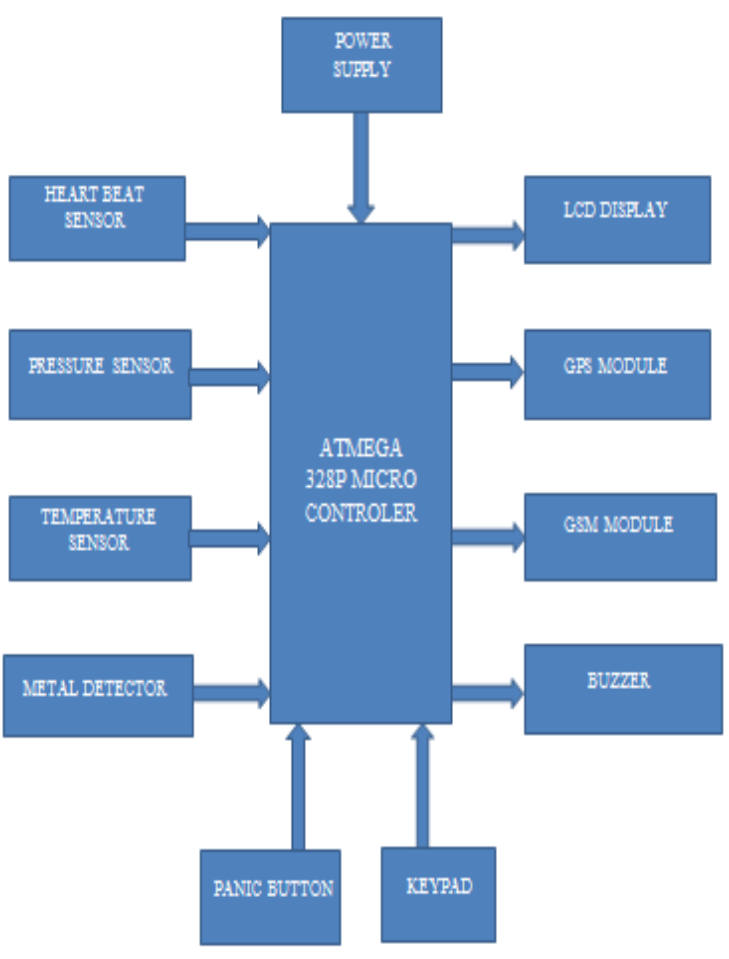

Fig 2.1.Block diagram

\section{III.DESCRIPTION}

\section{A. Heart beat sensor}

Heart beat sensor is designed to give digital output of heat beat when a finger is placed on it. When the heart beat detector is working, the beat LED flashes with each heart beat. This digital output can be connected to microcontroller directly to measure the Beats Per Minute (BPM) rate. It works on the principle of light modulation by blood flow through finger at each pulse.

\section{B. Pressure sensor}

A pressure sensor usually acts as a transducer; it generates a signal as a function of the pressure imposed. Pressure sensors are used for control and monitoring of systolic and diastolic pressure of blood flow.

C. Temperature sensor 
The LM35 series are precision integrated circuit temperature sensors, whose output voltage is linearly proportional to the Celsius (Centigrade) temperature. As it draws only $60 \mu \mathrm{A}$ from its supply, it has very low self-heating, less than $0.1^{\circ} \mathrm{C}$ in still air. The $\mathrm{LM} 35$ is rated to operate over a $-55^{\circ}$ to $+150^{\circ} \mathrm{C}$ temperature range.

D. Metal detector

Metal detectors are used to detect the buried landmines. It works on the principle of electromagnetic induction. The coils present in the metal detectors creates an electromagnetic field. The mines are usually made up of metal and this electromagnetic field induces an eddy current in the metal objects. This eddy current in turn creates its own electromagnetic field. Due to this field an opposite current is generated in the coils of metal detector. The metal detector controller senses this current and generates a signal indicating presence of mine.

\section{E.Atmega328P}

The ATmega328P is a low-power CMOS 8-bit microcontroller based on the AVR enhanced RISC architecture. By executing powerful instructions in a single clock cycle, the ATmega328P achieves throughputs approaching 1 MIPS per $\mathrm{MHz}$ allowing the system designer to optimize power consumption versus processing speed.

\section{F.GSM module}

This document describes the hardware interface of the simcom sim300 module that connects to the specific application and the air interface. As $\operatorname{sim} 300$ can be integrated with a wide range of applications, all functional components of $\operatorname{sim} 300$ are described in great detail. this document can help you quickly understand sim 300 interface specifications, electrical and mechanical details

G.GPS module

GPS-634R" is a highly integrated smart GPS module with a ceramic GPS patch antenna. The antenna is connected to the module via an LNA. The module is with 51 channel acquisition engine and 14 channel track engine, which be capable of receiving signals from up to 65 GPS satellites and transferring them into the precise position and timing information that can be read over either UART port or RS232 serial port. Small size and high-end GPS functionality are at low power consumption, Both of the LVTTL-level and RS232 signal interface are provided on the interface connector, supply voltage of $3.6 \mathrm{~V} \sim 6.0 \mathrm{~V}$ is supported.

\section{H. Panic button}

A panic alarm is an electronic device designed to assist in alerting somebody in emergency situations where a threat to persons or property exists. A panic alarm is frequently but not always controlled by a concealed panic alarm buttonThe alarm can be used to request emergency assistance during wars. Some systems can also activate closedcircuit television to record or assess the event.

\section{IV.WORKING}

\section{A. Data acquisition mode}

This paper has an idea of tracking the soldier and navigation between soldier to soldier such as knowing their heart rate, temperature, pressure of them during the war, which enables the army personnel to plan the war strategies. Base 
station gets location of soldier from GPS. This system also acquires data about the landmines which helps the soldiers to prevent some accidents during wars.

B. Transmission and receiving mode

The data which are acquired from the biosensors and metal detector are transmitted using GSM module to both the soldiers and the army base station if any abnormality is detected. The data are received via sms with the particular abnormality and location of the soldiers.

\section{V.RESULTS}

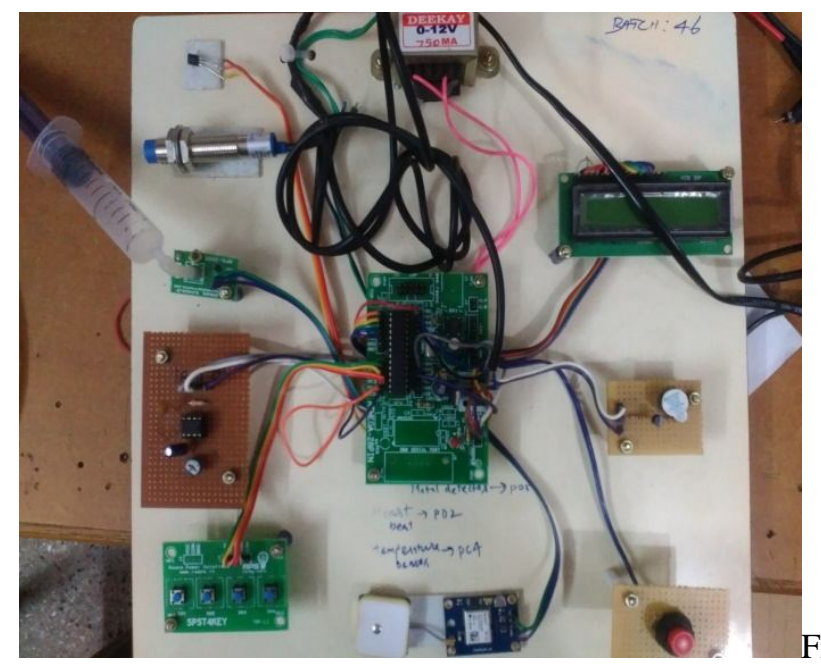

Fig 5.1. Hardware implementation unit

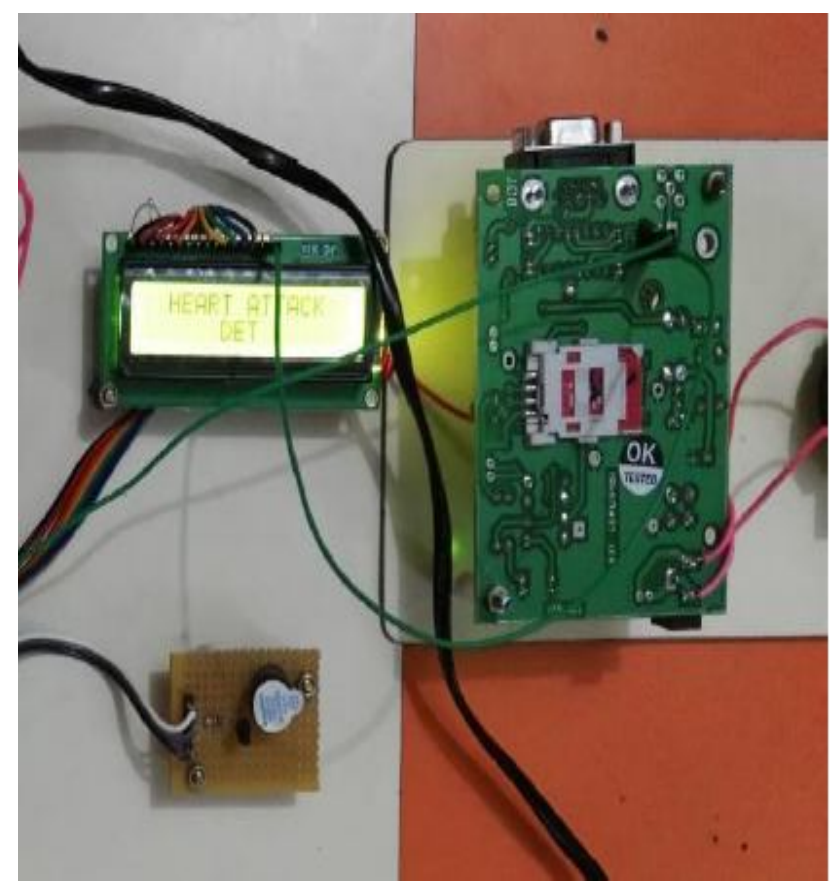

Fig 5.2 Shows the output of health monitoring unit

\section{VI.CONCLUSION}


GPS finds location of each soldier, thus gives safety for soldiers. As GPS coordinates are available for almost all area of earth so soldier can be tracked anywhere at any time. We can provide emergency help in case of bad health of soldier and by checking health status of soldier's. we can improve safety of soldier. This system also helps to provide real time information. Using this system we can reduce casualties of war. It also helps to giving critical information's and warnings to the soldiers and can apply more of them to the current weak locations. Thus we can conclude that these kinds of devices are very helpful for ensuring security to the soldiers.

\section{.REFERENCE}

[1] Govindaraj A. and Dr. S. Sindhuja Banu -"GPS based soldier tracking and health indication system with environmental analysis." - International journal of enchanced research in science technology and engineering, ISSN: start initialise ldc, serial communication display welcome message read and display gps location, body temp, heart rate send data to remote base station E-ISSN: 2321-9637 294 2319_7463 vol.2 Issue 12, December_2013 pp: (46-52) Page no(s) 46, 51.

[2]. Hock Beng Lim, Di Ma, Bang Wang, Zbigniew Kalbarczyt, Ravishankar k, Iyer, Kenneth L, Watkin, A soldier Helth Monitoring System for Military Application 2010 international conference on body network.

[3]. P.S. Kurhe, S.S. Agrawal, "Real Time Tracking and Health Monitoring System of Remote Soldier Using ARM 7”, International Journal of Engineering Trends and Technology, ISSN: 2231-5381, Volume 4, Issue 3, No. 1, March 2013, pp: (311-315).

[4]. Ekta Madhyan, Mahesh Kadam, "A Unique Health Care Monitoring System Using Sensors and ZigBee Technology", International Journal of Advanced Research in Computer Science and Software Engineering, ISSN: 2277-128X, Volume 4, Issue 6, June 2014, pp: (501-509). 